\title{
Tailored WBGT as a heat stress index to assess the direct solar radiation effect on indoor thermal comfort
}

\author{
Shayan Mirzabeigi ${ }^{a}$, Behrooz Khalilinasr ${ }^{b}$, Andrea G. Mainini ${ }^{b}$, Juan D. Blanco \\ Cadena $^{\mathrm{b}}$, Gabriele Lobaccaro ${ }^{\mathrm{c}}$ \\ ${ }^{\text {a }}$ Department of Sustainable Resources Management, State University of New York College of Environmental Science and \\ Forestry, Syracuse, NY, USA \\ ${ }^{\mathrm{b}}$ Department of Architecture, Built Environment and Construction Engineering, Politecnico di Milano, Milan, Italy \\ ${ }^{c}$ Department of Civil and Environmental Engineering, Faculty of Engineering, Norwegian University of Science and \\ Technology, Trondheim, Norway
}

\section{Abstract}

Uncontrolled solar radiation and the related effects on occupant productivity can lead to considerable indoor thermal discomfort in office environments. In this paper, the Radiance Daylight Coefficient (DC) method is used to assess incoming solar radiation and consequent indoor thermal discomfort through delta mean radiant temperature ( $\triangle \mathrm{MRT})$. The $\triangle \mathrm{MRT}$ allows expressing an adjusted predicted mean vote (Adjusted PMV). Under the conditions of direct solar radiation, the Adjusted PMV value surpasses the applicability range of the standard PMV in terms of MRT value. To overcome this limitation, the assessment of the effect of incoming shortwave solar radiation is expressed in the heat stress index of wet bulb globe temperature (WBGT). This procedure was tested under a variety of climatic conditions (e.g., Sol-air temperature) to estimate dissatisfaction in indoor office environments located in Milan (Italy) for an occupant positioned at different distances from the fenestration ( 0.75 $\mathrm{m}, 1.25 \mathrm{~m}$, and $1.75 \mathrm{~m}$ ) and exposed to direct solar radiation (e.g., without shading devices). The condition with no shading device was then compared with the condition with shaded glazing to test the impact of the solar radiation on the indoor thermal stress conditions. The results reported through $\triangle$ WBGT allow the estimation of the heat stress conditions on an annual basis when $\Delta \mathrm{WBGT}>0$. Finally, it is proposed that the metric of Annual Radiation Heat Stress (ARHS) should include $\triangle$ WBGT and assess the heat stress spatially due to the incoming direct solar radiation.

\section{Keywords}

Indoor thermal comfort; Solar radiation; Radiance DC method; WBGT.

\section{Nomenclature}


29 Adjusted MRT: adjusted mean radiant temperature $\left({ }^{\circ} \mathrm{C}\right)$

30 Adjusted PMV: adjusted predicted mean vote (-)

31 ARHS: annual radiation heat stress (\%)

32 CAV: clothing adjustment value $\left({ }^{\circ} \mathrm{C}\right)$

$33 \mathrm{C}_{\mathrm{p}}$ : specific heat capacity at constant pressure $(\mathrm{J} / \mathrm{kg} \mathrm{K})$

34 ERF: effective radiant field $\left(\mathrm{W} / \mathrm{m}^{2}\right)$

$35 \quad \mathrm{E}_{\text {solar: }}$ total shortwave solar radiant flux $\left(\mathrm{W} / \mathrm{m}^{2}\right)$

$36 \quad \mathrm{f}_{\text {eff: }}$ fraction of body exposed to sun (-)

$37 \mathrm{~h}_{\mathrm{r}}$ : radiation heat transfer coefficient $\left(\mathrm{W} / \mathrm{m}^{2} \mathrm{~K}\right)$

$38 \quad \mathrm{I}_{\mathrm{cl}}$ : thermal insulation index (clo)

$39 \quad i_{m}$ : permeability index (-)

40 M: metabolic rate (W)

41 MRT: mean radiant temperature $\left({ }^{\circ} \mathrm{C}\right)$

42 PMV: predicted mean vote (-)

43 PPD: predicted percentage of dissatisfied (\%)

$44 \mathrm{p}_{\mathrm{v}}$ : water vapor pressure $(\mathrm{Pa})$

45 RH: relative humidity (\%)

$46 \quad \mathrm{~T}_{\mathrm{a}}$ : air temperature $\left({ }^{\circ} \mathrm{C}\right)$

$47 \quad \mathrm{~T}_{\mathrm{c}}$ : cooling set point $\left({ }^{\circ} \mathrm{C}\right)$

$48 \quad \mathrm{~T}_{\mathrm{g}}$ : black globe temperature $\left({ }^{\circ} \mathrm{C}\right)$

$49 \mathrm{~T}_{\mathrm{h}}$ : heating set point $\left({ }^{\circ} \mathrm{C}\right)$

$50 \mathrm{~T}_{\mathrm{nwb}}$ : natural wet bulb temperature $\left({ }^{\circ} \mathrm{C}\right)$

$51 \mathrm{~T}_{\mathrm{pwb}}$ : psychrometric wet bulb temperature $\left({ }^{\circ} \mathrm{C}\right)$

$52 \quad \mathrm{~T}_{\text {sol: }}$ solar transmittance (-)

53 U: thermal transmittance $\left(\mathrm{W} / \mathrm{m}^{2} \mathrm{~K}\right)$

54 v: air speed (m/s)

55 WBGT: wet bulb globe temperature $\left({ }^{\circ} \mathrm{C}\right)$

56 WBGT $_{\text {eff: }}$ effective wet bulb globe temperature $\left({ }^{\circ} \mathrm{C}\right)$

57 WBGT $_{\mathrm{LW}}$ : longwave wet bulb globe temperature $\left({ }^{\circ} \mathrm{C}\right)$

$58 \quad$ WBGT $_{\text {ref: }}$ : reference wet bulb globe temperature $\left({ }^{\circ} \mathrm{C}\right)$ 
59 WBGT $T_{\text {sw: }}$ shortwave and longwave wet bulb globe temperature $\left({ }^{\circ} \mathrm{C}\right)$

$60 \mathrm{x}$ : the thickness of assigned element (m)

$61 \alpha_{\mathrm{LW}}$ : longwave radiation absorptivity (-)

62 $\alpha_{\text {sw: }}$ shortwave radiation absorptivity (-)

63 MMRT: delta mean radiant temperature $\left({ }^{\circ} \mathrm{C}\right)$

$64 \Delta$ WBGT: delta wet bulb globe temperature $\left({ }^{\circ} \mathrm{C}\right)$

$65 \lambda$ : thermal conductivity $(\mathrm{W} / \mathrm{mK})$

66 $\rho$ : thermal density $\left(\mathrm{kg} / \mathrm{m}^{3}\right)$

$67 \rho_{\text {sol }}$ : reflectance (-)

\section{Introduction}

69

In many parts of the world humans commonly spend most of their life indoors, and the majority of the population of the world works in an office-like layout setting [1]. As such, it is beneficial to better analyze the indoor office environment, especially thermal comfort, which is known to impact occupants productivity [2] and well-being [3]. Thermal comfort could be expressed as a condition under which the user perceives satisfaction with the perceived thermal environment [4]. This condition is not only affected by objective quantitative variables, but also subjective qualitative ones related to the habits of the user [1]. Delivering and/or maintaining overall thermal comfort in a building is often a complex task. Multiple environmental parameters (e.g., air temperature, surface temperature, relative humidity, mean radiant temperature, wind speed, and direction) and other geometrical and physical factors(e.g. window location, orientation and dimensions, occupants clothing, user activity, position, and mood), have been proven to strongly affect the thermal comfort perception of occupants [1]. The parameters directly related to the building users differ per individual due to different factors (e.g. age, sex, metabolic rate) $[5]$.

The first instrumental work in the area of thermal comfort and occupants perception was performed by Fanger (1970) [6]. He introduced an analytical model to estimate thermal comfort perception that combines physiological parameters with human behavior variables to define the two synthetic comfort indices as the predicted mean vote (PMV) and the predicted percentage of dissatisfied (PPD) [7], which is the proportion of people dissatisfied with the thermal conditions in indoor environment, considering it too warm or too cold [7]. Fanger's thermal comfort model (PMV model) was based on subjective surveys and rigorous experiments involving subjects wearing different levels of clothing and engaging in different levels of activity who were exposed to different steady-state 
conditions in a controlled indoor environment. This model is generally applied when it is necessary to estimate

the predicted thermal comfort condition of a mechanically heated, cooled, or ventilated indoor space.

90 However, researchers have found that when this model is applied for a building without mechanical systems, it is inaccurate in predicting the occupant's thermal discomfort. The results showed that PMV could underestimate the thermal sensation by up to $13 \%$ in summer and overestimate it by up to $35 \%$ in winter within naturally ventilated buildings [8].

94 De Dear and Brager (1998) [9] have stated that occupants have a positive attitude towards adapting to the environmental conditions, which was not considered during the development of the PMV model. De Dear and Brager proposed an alternative approach, known as the adaptive comfort model. This approach was based on field experiments and analysis of human acceptability of a thermal environment that considered adaptive behavior, physiological and psychological adjustments [9]. Similar approaches have been recalled in ASHRAE-55 [4] and EN-16798 [10]. Among the environmental conditions, ambient temperature and humidity ratio play a decisive role in the occupants' thermal comfort. However, solar radiation falling over the user's body is also one of the most influencing variables that contribute to shaping the perceived thermal sensation of a user in an indoor space [11]. In that regard, solar radiation requires deeper analysis and more consideration due to its influence on the thermal

104 perception of feeling warmer, which can subsequently have negative impacts on occupants' productivity [12]. Therefore, it is fundamental to consider the effect of shortwave solar radiation on the occupant's indoor thermal comfort.

This research is motivated to provide a new perspective in assessing the effect of incoming shortwave solar radiation falling over the occupants and in estimating the indoor thermal comfort. To that end, by exploiting its lower sensitivity to strong variations of the adjusted mean radiant temperature (Adjusted MRT) perceived by the user, the possible application of the heat stress index of wet bulb globe temperature (WBGT) is considered as an alternative for the PMV model.

112 Studies using the WBGT approach have assessied the thermal comfort in an indoor environment, especially working environments with hot working conditions However, the study presented here focuses on the Delta Value

114 approach. Its novelty is based on the implementation of a modified version of the WBGT for indoor thermal comfort assessment, evaluated using the Radiance's Daylight Coefficient (DC) method, a parametric and climatebased approach, which allows the inclusion of the shortwave contribution of the solar radiation over the human body. 
118 Section 2 (Background) presents the state-of-the-art of the research field framing this study. Section 3

119 (Methodology) defines the computer-aided simulation workflow and describes the procedure for calculating the 120 modified version of WBGT. The description includes the metric Annual Radiation Heat Stress (ARHS) to assess

121 the heat stress spatially due to the incoming direct solar radiation. Next, s Section 4 (Results and discussion)

122 presents the outcomes of the simulation and their discussion through graphics (e.g., false-color plots) and 123 analytically using the proposed metrics (i.e. WBGT, $\triangle$ WBGT:). The Section 5highlights and discusses the main

124 limitations of the study. Finally, Section 6 (Conclusions) summaries the study and the most significant outcomes.

\section{Background}

\subsection{The effects of shortwave solar radiation on users' perception of thermal comfort}

127 Uncontrolled direct solar radiation flux often causes significant visual (e.g., glare) and thermal (e.g., overheating, 128 cooling load) issues, especially in buildings with unshaded glazing [12]. International standards ISO-7730 [7] and EN-16798 [10], which are mainly based on a generic radiosity approach, do not include shortwave radiation when calculating comfort. However, shortwave solar radiation could be the most substantial component of total solar radiation gathered indoors [13]. Although direct solar radiation is considered in every dynamic simulation, the analysis of the effect of solar radiation directly falling on the occupant is neglected in different comfort models. It is also necessary to underline that when the uncontrolled direct solar radiation falls on the occupants, it can also influence peak energy loads, such as an increased energy consumption resulting from the need of users to mitigate the perceived thermal condition by using building systems [14].

136 Complex human models have been elaborated and proposed that allow designers and modelers to estimate the body core and skin temperature of the occupant based on the surrounding thermal environment. Skin temperatures can then be used to determine local thermal sensation as input for comfort assessment [14], [15]. In addition, there are models relying on equivalent temperature values or advanced thermal comfort models, like the one presented by the University of California Berkeley [12], [16], that can be used to predict human comfort in transient, nonuniform thermal environments.

142 In the case of direct solar radiation falling on the occupant, ASHRAE-55 [4] introduces two approaches for dealing with this issue when determining the thermal comfort condition [17]: (1) the prescriptive approach, which is

144 applicable only when specific criteria are met (see Appendix C in [4]). It asserts that when these conditions arise, 145 a mean radiant temperature (MRT) increase of $2.8^{\circ} \mathrm{C}$ (higher than average air temperature) can be used. (2) the 146 performance approach, based on the work of Arens et al. [12], which calculates Adjusted MRT by summing up 
147 the contributions of the calculated longwave and shortwave MRT.. Under these conditions, MRT depends on solar

148 radiation distribution, surrounding context, direct and indirect solar transmittance of the fenestration system,

149 occupant position and posture, body exposure, sun position, irradiance value, and clothing absorptivity.

150 A limitation of the performance approach method is that the incoming direct and diffuse solar radiation considers

151 a fixed fraction of the sky vault and a projected area of the person exposed to radiation for static scenarios [14].

152 The point-in-time results can also lead to an inaccurate understanding of the performance of the fenestration

153 systems, especially in the case of solar shading systems that are considered to manage solar radiation flux for the

154 whole year [14].

155 As reported in [14], by applying the Radiance ray-trace method and DC method, the intensity of total solar radiation falling on the occupant's body can be estimated on an annual basis, with the aim of predicting the differences in indoor thermal comfort of occupants.

158 Zani et al. (2019) [17] introduced the Annual Discomfort Radiation index (ARD index) to spatially assess the discomfort caused by solar radiation. This index shows areas on the floor plan that represents uncomfortable thermal conditions. It works by mapping the variation of delta mean radiant temperature $(\Delta \mathrm{MRT})[17]$, and it is based on the concept of an annual metric like Daylight Autonomy (DA) [18].

\subsection{Comfort conditions assessment considering the shortwave solar radiation}

163

164

165

166

167

The PMV equation uses four environmental variables: air temperature $\left(\mathrm{T}_{\mathrm{a}}\right)$, mean radiant temperature (MRT), air speed (v), relative humidity $(\mathrm{RH})$; and two subjective variables: clothing thermal insulation index $\left(\mathrm{I}_{\mathrm{cl}}\right)$ and metabolic rate $(\mathrm{M})$. It predicts thermal sensation ratings of occupants on the ASHRAE seven-point thermal sensation scale [7]. Based on ISO-7730 [7], these values are required to be within a valid range when computing PMV, which are: "M: 0.8 to 4 met, $\mathrm{I}_{\mathrm{cl}}: 0$ to 2 clo, $\mathrm{T}_{\mathrm{a}}: 10$ to $30{ }^{\circ} \mathrm{C}, \mathrm{MRT}: 10$ to $40{ }^{\circ} \mathrm{C}$, v: 0 to $1 \mathrm{~m} / \mathrm{s}, \mathrm{P}_{\mathrm{v}}: 0$ to 2700 Pa".

The variations between reported and predicted thermal sensation have been attributed to errors in measurements, which relate to inaccuracies in the input parameters required for calculating PMV, especially in assessing the average clothing insulation values and metabolic rate. Errors have also been associated with contextual effects [19]. The PMV model is based on experimental environments (e.g., climate chamber), that require a more indepth study, as stated by Beizaee et al. (2012), [19] in comparison to the occupant's usual environmental settings. The PMV model is certainly the most widely used and accepted thermal comfort index but needs to be more robust to increase its applicability. Extreme conditions (e.g., those where the occupant is under direct solar radiation) 
177 Adjusted MRT values that exceed the MRT validity range. The interpretation of these results is rather uncertain 178 since cases of PMV > +3 were not described within Fanger's model (i.e. no information on the degree of warmth 179 perceived). Solving this issue could also enable the analysis of outdoor environments with the same procedure.

180 The CBE Thermal Comfort Tool includes both ASHRAE-55 and EN-16798 for its comfort calculation [20], [21]. An example is shown in Figure 1 using this tool [21] under EN-16798 settings. It displays the calculation for a time of the year for ASHRAE BESTEST in Milan (with ERF value of $91.0 \mathrm{~W} / \mathrm{m}^{2}$ ). The value of MRT, without the contribution of shortwave solar radiation, is estimated to be $28.0^{\circ} \mathrm{C}$, which corresponds to a PMV of 0.5

184 (Figure 1a). Under the same scenario, considering an adjustment in MRT due to solar radiation results in a condition of Adjusted MRT equal to $49.8^{\circ} \mathrm{C}$, which corresponds to a PMV of 4.4 (Figure 1b). The PMV increases 3.9 points when the shortwave contribution of solar radiation is considered. However, the Adjusted MRT value surpasses the applicability range due to the fact that it does not comply with the standard; in that regard, none outcome is obtained from the CBE Thermal Comfort Tool..
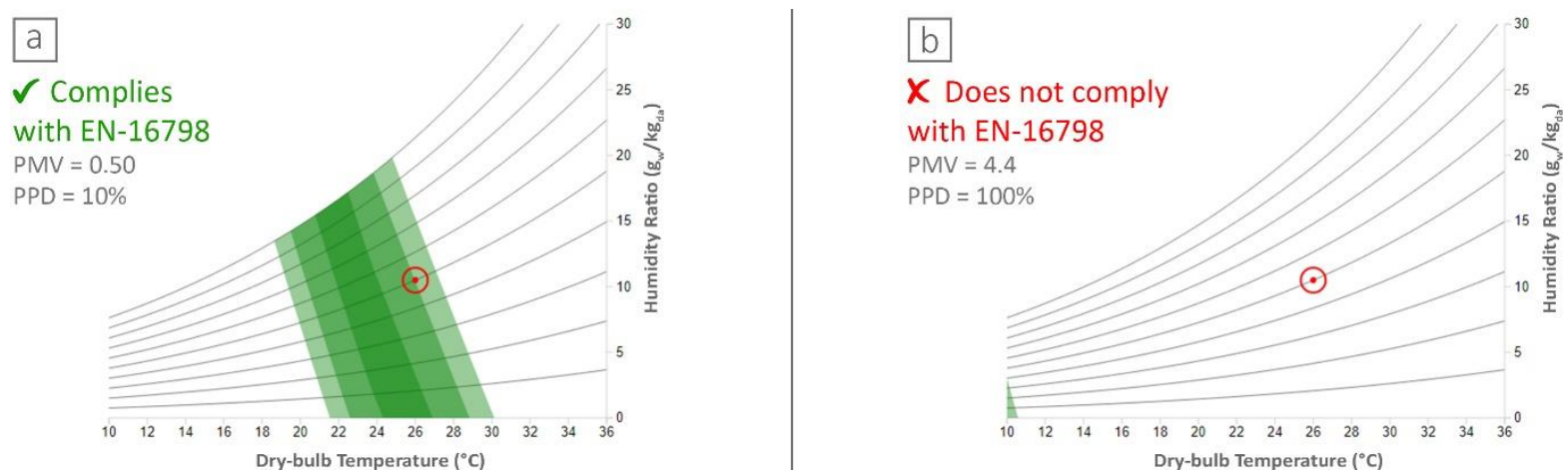

Figure 1 - Example of using the CBE Thermal Comfort Tool under EN-16798 (visualization with psychrometric chart) to compare predicted PMV: a) without solar radiation, and b) with solar radiation (under apparent comfortable conditions of $T_{a}=26^{\circ} \mathrm{C}, v=0.1 \mathrm{~m} / \mathrm{s}, \mathrm{RH}=50.0 \%, I_{c l}=0.6$ clo and $M=1 \mathrm{met}$ ).

\subsection{Evaluation of solar radiation effects under proper heat stress index}

194 The most important aspect of considering shortwave solar radiation as a cause of local discomfort is related to the methodology used to assess the caused dissatisfaction. Scenarios with direct solar radiation flux that carry large amounts of shortwave radiation and change occupant thermal comfort perception are not unusual, and the current definition of the PMV model provides a certain degree of uncertainty in which, for certain climatic conditions and room location, it is not possible to adequately assess or rate the thermal environmental perception. 
In this study, solar radiation has been introduced as a heat stress phenomenon that can cause dissatisfaction for occupants both indoors and outdoors. To do so, heat stress is expressed through a suitable index. The effect of architectural design on outdoor thermal comfort is also unavoidable, and it is rare to find tools and methods that allow the evaluation of thermal comfort for both indoor and outdoor spaces [22]. The present study improves the evaluation of indoor comfort by taking into account influencing outdoor parameters (e.g., airspeed, ventilation, urban morphology, finishing materials, surface temperature, shortwave solar radiation), which could help to assess the dissatisfaction caused by shortwave solar radiation and ease the management of indoor discomfort in preliminary design stages. The focus of this study is to consider the solar radiation that significantly influences the MRT and consequently the comfort conditions.

The environmental thermal aspect constitutes a relevant issue related to human health and well-being. It comprises both heat-exchange conditions (i.e. stress) and the physiological responses (i.e. strain) [23], [24]. The heat stress indices are useful to understand the effects of the thermal environment on the thermal perception of humans [25].

211 Zamanian et al. (2017) [24] compared different thermal indices such as Wet bulb globe temperature (WBGT),

212 Universal thermal climate index (UTCI), Subjective temperature index (STI), Predicted heat stress (PHS), and

213 Humidex. Moreover, they shared the concern of potential risks of working in a hot environment related to physiological responses, or strain, such as a change in skin and core body temperature and heart rate. The association of thermal indices with some physiological parameters such as blood pressure, pulse rate, and skin temperature were studied by Zamanian et al., and based on the results of linear regression analysis, a significant correlation was found between skin temperature and WBGT. However, the results showed no significant relationship between physiological response and other thermal stress indices such as UTCI, PHS, STI, and Humidex [24].

Therefore, the WBGT was chosen as a proper heat stress index because (1) its versatility allows it to be applied in both indoor and outdoor comfort analysis; (2) solar radiation is a phenomenon that is firstly sensed by the skin, and there is a strong link between the WBGT and skin temperature. Consequently, the WBGT allows a more reasonable assessment of the thermal dissatisfaction caused by the contribution of the solar radiation and it leads to defining new ways to control thermal discomfort.

\section{Methodology}

In this work, the heat stress index of WBGT is implemented to overcome the existing limitations of PMV and 
model's reliability, this heat stress index can mitigate the impact of extreme events. The use of the Radiance DC method on the Grasshopper platform allows the calculation of the hourly incident solar radiation landing on the human body. The elaboration of a script on the Grasshopper platform allows the detailed and spatial estimation of the WBGT affected by the solar radiation and the comparison with the different thermal stress indices

\subsection{The simulation framework}

In this Section the workflow is presented to introduce the Adjusted MRT in the calculation procedure for the WBGT and explain how to post-process the results in order to introduce a spatial and climate-based thermal perception index. The Adjusted MRT predicts the variation of the heat stress of occupants due to the solar radiation across the floor plan to be predicted and the total discomfort hours to be evaluated. A climatic based workflow is used to evaluate the effect of direct solar radiation on human thermal comfort across indoor spaces for one year. The workflow is based on validated simulation engines, Radiance for daylight and solar radiation analysis and Energy Plus for energy analyses through Ladybug Tools, to conduct simulations in in the Grasshopper environment. This approach represents an alternative to the method of ASHRAE-55 (appendix

241 C) by calculating the WBGT heat stress index.

242 The workflow allows the calculation of the annual hourly values of total radiation (e.g., direct, reflected, and 243 diffuse) on the human body with the Radiance DC method and, subsequently, ERF, $\triangle \mathrm{MRT}$, and the consequent value of $\triangle \mathrm{WBGT}$. The analysis conducted in the Grasshopper platform allows the automatizing of the workflow for multiple annual simulations. It is tested for an occupant placed at different distances from the fenestration and exposed to direct solar radiation and computes the degree of heat stress in an indoor environment.

247 Based on this procedure, the Annual Radiation Heat Stress metric (ARHS), as a modified climate-based index, is presented to assess spatially extreme heat stress conditions. Moreover, the methodology is tested to provide information on how well a fenestration system performs in controlling the incoming solar radiation, in terms of occupants' thermal comfort, and estimating the heat stress caused by the solar radiation during the year in an office environment.

As shown in Figure 2, the simulation workflow is divided into six parts. In Section 3.1.1, the Rhinoceros scene and manikin modeling are described. Section 3.1.2 describes the Radiance DC method. Thanks to this method, the hourly intensity of solar radiation that is transmitted through the fenestration system and lands on the human body is calculated. Then, Section 3.1.3 briefly explains the Energy Plus simulation to calculate the air temperature, relative humidity, surface temperatures, airspeed, and longwave MRT. Section 3.1.4 introduces the procedure to calculate the delta mean radiant temperature value. In Section 3.1.5, the calculation of WBGT is described. 


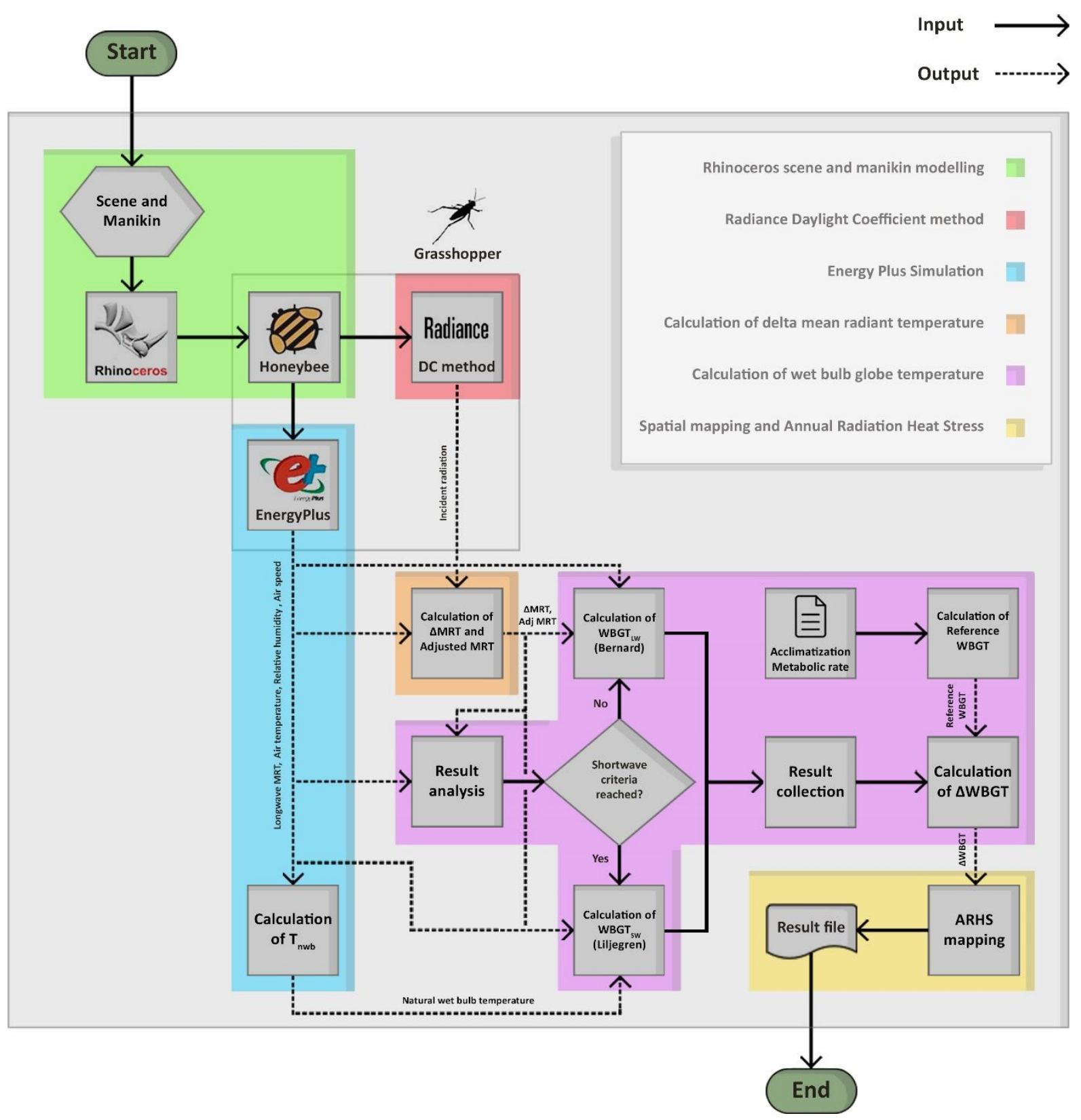

Figure 2 - Simulation workflow for indoor thermal comfort analysis. The six main parts have been clustered and differentiated with colors.

\subsubsection{Rhinoceros scene and manikin modelling}

264 Rhinoceros geometry information is created and handled via Grasshopper visual language [26]. Honeybee plugin within Ladybug tools is used to generate the input text files for Radiance and Energy Plus simulations. The manikin is constituted by 133 planar mesh faces to calculate the total solar radiation falling on each manikin's body. 


\subsubsection{Radiance Daylight Coefficient method}

269 The DC method described by Zani et al. (2018) [14] is used in the simulation workflow to compute the incoming 270 solar radiation falling on the manikin. The DC (Two-Phase) method includes the calculation of the Daylight

271 Coefficient matrix, considering sky conditions and scene characteristics, and sky vector (matrix), based on direct

272 and diffuse solar radiation. The next step, after identifying matrices, is matrix multiplication to compute the

273 irradiance value. Incident solar radiation is then calculated for each face mesh of the manikin, for each hour of the

274 year. This process is repeated for each manikin's location in the room scene, described later in chapter 3.2.

\section{$275 \quad$ 3.1.3 Energy Plus simulation}

276 The geometrical data in Rhinoceros is transferred into an IDF text file. The Energy Plus engine is used for the 277 calculation of the air temperature, relative humidity, surface temperatures, and longwave MRT in the room. The 278 longwave MRT is calculated considering the surface temperatures of walls, glazing surfaces, and the 279 corresponding view factor for the exact user position. These values are later used to calculate the WBGT.

\subsubsection{Calculation of delta mean radiant temperature}

281 The solar radiation falling over the manikin, discretized in polygonal patches, is then transformed into the ERF and shortwave $\triangle \mathrm{MRT}$, which reflects the potential increase of MRT caused by the solar radiation [12] for a person exposed to solar radiation in the indoor environment (see equations (1) and (2)). These measures are both mainly affected by the solar absorbance of the human skin, and the percentage of the exposed surface of the body and the incident solar radiation.

$\Delta \mathrm{MRT}=\frac{\mathrm{ERF}}{\mathrm{f}_{\mathrm{eff}} \mathrm{h}_{\mathrm{r}}}$

\subsubsection{Wulb globe temperature calculation methods}

The WBGT is defined as a heat stress index, and it is a screening method for the presence or absence of heat stress described in the ISO-7243 [27]. The level of heat stress is dependent on the heat transfer between the body and the surrounding ambient environment, the heat production inside the human body as a result of physical activity, and the clothing worn, which alters the heat exchange, $\mathrm{I}_{\mathrm{clo}}$. Furthermore, the same standard [27] states that the WBGT is calculated based on the measured natural wet bulb temperature $\left(\mathrm{T}_{\mathrm{nwb}}\right)$ and black globe temperature $\left(\mathrm{T}_{\mathrm{g}}\right)$, considering direct solar radiation, either outdoors or indoors. 
296 is proposed when only the longwave solar radiation is considered, while eq. (4) can be used when both long and

297 shortwave solar radiation are included.

$298 \quad \mathrm{WBGT}_{\mathrm{LW}}=0.7 \mathrm{~T}_{\mathrm{nwb}}+0.3 \mathrm{~T}_{\mathrm{g}}$

$299 \mathrm{WBGT}_{\mathrm{SW}}=0.7 \mathrm{~T}_{\mathrm{nwb}}+0.2 \mathrm{~T}_{\mathrm{g}}+0.1 \mathrm{~T}_{\mathrm{a}}$

300 The calculation of WBGT is performed by assuming standard and fixed work clothing $\left(\mathrm{I}_{\mathrm{cl}}=0.6 \mathrm{clo}, \mathrm{i}_{\mathrm{m}}=0.38\right)$ for 301 an average clothing condition [27]. To consider the effect of actual clothing other than standard work clothing in 302 the calculation of the WBGT, its value can be calculated by the clothing adjustment value (CAV). The result is 303 called Effective wet bulb globe temperature ( $\mathrm{WBGT}_{\text {eff }}$ ), which is an estimation of the heat stress of the actual 304 clothing used as an equivalent environment [27], and it can be computed according to the eq. (5).

306 The WBGT $_{\text {eff }}$ values are computed with eq. (1) or (2), and (3), which are then compared with Reference WBGT

307 (WBGT $\left.\mathrm{Wef}_{\text {ref }}\right)$ values to estimate the heat stress conditions. Figure 3 shows that the $\mathrm{WBGT}_{\text {eff }}$ value is compared with

308 WBGT $_{\text {ref }}$ value, and the result will be delta wet bulb globe temperature $(\triangle \mathrm{WBGT})$. There will be heat stress

309 conditions if $\triangle \mathrm{WBGT}$ is positive, in which case it would be important to directly mitigate the heat stress [27];

310 otherwise, there will be a condition without heat stress.

311 The WBGT $_{\text {eff }}$ depends on the concept of acclimatization, which is defined based on the ISO-7243 [27].

312 Acclimatization occurs when a person is exposed to hot working conditions for at least seven days before the 313 analysis period. If this is not the case, the person will be in a non-acclimatized condition.

314 Figure 3 also shows the relationship between metabolic rate and WBGT $_{\text {eff }}$ (with standard work clothing). The 315 straight line shows the limit of acceptable heat stress exposure for normal, healthy, acclimatized workers, and the 316 dashed line represents a sustainable level of heat stress exposure for normal, healthy, non-acclimatized workers, 317 where $115 \mathrm{~W}<\mathrm{M}<520 \mathrm{~W}$. For acclimatized people, eq. (6) can be applied, while for non-acclimatized people, eq. (7) is included in the standard [27]. 


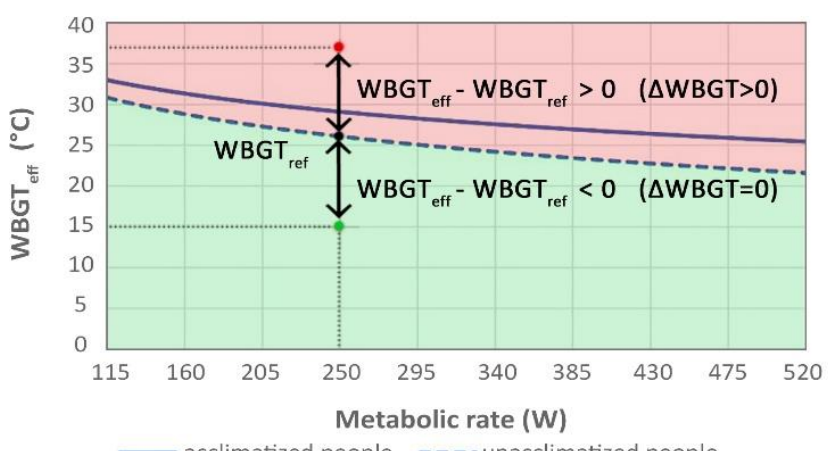

320 Figure 3 - Example comparison of WBGT eff and reference value limits by the metabolic rate (eq. (6) and (7) are used to

321 draw WBGT ref lines from ISO-7243 [27]).

322 WBGT $_{\text {ref }}=56,7-11,5 \log _{10}(\mathrm{M})$

323 WBGT $_{\text {ref }}=59,9-14,1 \log _{10}(\mathrm{M})$

324 Table 1 shows the classification of levels of metabolic rate, including resting, low, moderate and high metabolic 325 rates. In the section of Results, different outcomes are rendered based on the defining WBGT ref $_{\text {values concerning }}$ 326 this classification of levels of metabolic rate.

327 Table 1 - Classification of levels of metabolic rate extracted from [28] and corresponding WBGT ref values of the 328 acclimatized and not-acclimatized person.

\begin{tabular}{lccc}
\hline Class & $\mathbf{M}(\mathbf{W})$ & $\begin{array}{c}\mathbf{W B G T}_{\text {ref }}\left({ }^{\circ} \mathbf{C}\right) \\
\text { for acclimatized }\end{array}$ & $\begin{array}{c}\mathbf{W B G T}_{\text {ref }}\left({ }^{\circ} \mathbf{C}\right) \\
\text { for non-acclimatized }\end{array}$ \\
& & person & person \\
\hline 0: Resting & $115(100-125)$ & 33.00 & 30.84 \\
1: Low metabolic rate & $215(125-235)$ & 29.88 & 27.01 \\
2: Moderate metabolic rate & $300(235-360)$ & 27.97 & 22.67 \\
3: High metabolic rate & $415(360-465)$ & 26.59 & \\
& & & \\
\hline
\end{tabular}

329 ISO-7243 [27] set specific requirements for the globe and natural wet bulb thermometer measurements for the 330 estimation of the WBGT index following the method presented in [29]. It is essential to understand if the WBGT can be calculated from meteorological measurements [30] and if it is possible to exploit the environment assessment databases available in the literature in which the mentioned parameters are provided [29]. 
333 Bernard and Pourmoghani [31] compared indoor measurements with calculated longwave wet bulb globe 334 temperature $\left(\mathrm{WBGT}_{\mathrm{LW}}\right)$. Their approach includes all meteorological variables as required by the WBGT 335 calculation and the uses heat exchange principles and measurements (of a wetted wick) for $\mathrm{T}_{\text {nwb }}$ [30], [31]. The 336 equations presented in Table 2 are used to calculate the $\mathrm{T}_{\text {nwb }}$ and not the WBGT. Unfortunately, their approach 337 does not involve estimating the temperature of the black globe directly exposed to sun rays and their theory and measurements refer mostly to indoor environments. Therefore, this method is not appropriate to calculate the

339 WBGT $_{\mathrm{Sw}}$, but it would be suitable for the calculation of the $\mathrm{WBGT}_{\mathrm{LW}}$.

Table 2 - Bernard's semi-empirical formula for $T_{n w b}[31]$.

\begin{tabular}{lll}
\hline Criteria & Equation & Ref. eq. \\
\hline $\mathrm{T}_{\mathrm{g}}-\mathrm{T}_{\mathrm{a}}>4{ }^{\circ} \mathrm{C}$ & $\mathrm{T}_{\mathrm{nwb}}=\mathrm{T}_{\mathrm{pwb}}+0.25\left(\mathrm{~T}_{\mathrm{g}}-\mathrm{T}_{\mathrm{a}}\right)+0.1 \mathrm{v}^{1.1}-0.2$ & $(8.1)$ \\
$\mathrm{T}_{\mathrm{g}}-\mathrm{T}_{\mathrm{a}}<4{ }^{\circ} \mathrm{C} ;$ & $\mathrm{T}_{\mathrm{nwb}}=\mathrm{T}_{\mathrm{pwb}}$ \\
$\mathrm{V}>3 \mathrm{~m} / \mathrm{s}$ & \\
Otherwise & $\mathrm{T}_{\mathrm{nwb}}=\mathrm{T}_{\mathrm{pwb}}-(0.96+0.069 \log )\left(\mathrm{T}_{\mathrm{a}}-\mathrm{T}_{\mathrm{pwb}}\right)$ \\
& \\
\hline
\end{tabular}

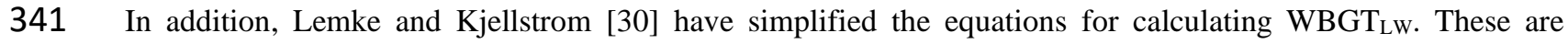
342 presented as eq. (9.1) and eq. (9.2) in Table 3.

343 Table 3 - Simplification for the calculation of $W B G T_{L W}[30]$.

\begin{tabular}{lll}
\hline Criteria & Equation & Ref. eq. \\
\hline $\mathrm{v}>3 \mathrm{~m} / \mathrm{s} ; \mathrm{T}_{\mathrm{nwb}}=\mathrm{T}_{\mathrm{pwb}} ; \mathrm{T}_{\mathrm{g}}=\mathrm{T}_{\mathrm{a}}$ & $\mathrm{WBGT}_{\mathrm{LW}}=0.7 \mathrm{~T}_{\mathrm{pwb}}+0.3 \mathrm{~T}_{\mathrm{a}}$ & $(9.1)$ \\
$0.03 \mathrm{~m} / \mathrm{s}<\mathrm{v} \leq 3 \mathrm{~m} / \mathrm{s}$ & $\mathrm{WBGT}_{\mathrm{LW}}=0.67 \mathrm{~T}_{\mathrm{pwb}}+0.33 \mathrm{~T}_{\mathrm{a}}-0.048 \operatorname{logv}\left(\mathrm{T}_{\mathrm{a}}-\mathrm{T}_{\mathrm{pwb}}\right)$ & $(9.2)$ \\
\hline
\end{tabular}

344 Liljegren et al. [32] used instead the heat exchange principles to calculate $\mathrm{T}_{\mathrm{nwb}}$ and $\mathrm{T}_{\mathrm{g}}$. Since their equations for 345 the calculation of the $\mathrm{T}_{\mathrm{g}}$ involve both the diffuse and direct solar radiation, their method is mostly applied for clear 346 as well as cloudy conditions. Additionally, the Liljegren et al. method includes all meteorological variables as 347 required by the WBGT calculation. They compared the calculated $\mathrm{WBGT}_{\mathrm{SW}}$ and measured WBGT, and found 348 that the differences were less than $1{ }^{\circ} \mathrm{C}$ for $95.0 \%$ of the time, except when the differences were attributed to equipment issues [30]. This method is preferred for calculating the $\mathrm{WBGT}_{\mathrm{SW}}$. Since Liljegren et al. have not 
351 WBGT $\mathrm{LW}$.

352 A summary of the methodologies used in this research for calculations of the WBGT is presented in Table 4.

Table 4 - The methodologies used for different calculations of the wet bulb globe temperature.

\begin{tabular}{llllll}
\hline Index & $\begin{array}{l}\text { Solar } \\
\text { radiation }\end{array}$ & $\begin{array}{l}\text { Method } \\
\text { based }\end{array}$ & Criteria & Air speed & Equation \\
& & & & \\
\hline WBGT & Long + short & Liljegren & $\mathrm{T}_{\mathrm{g}}-\mathrm{T}_{\mathrm{a}}>4$ & - & ${ }^{2}$ \\
& & & & \\
& wave & & ${ }^{\circ} \mathrm{C}$ & & \\
& radiation & & & & \\
& & & & & \\
& Only long & Bernard & $\mathrm{T}_{\mathrm{g}}-\mathrm{T}_{\mathrm{a}}<4$ & $\mathrm{v}>3$ & WBGT $_{\mathrm{LW}}=0.7 \mathrm{~T}_{\mathrm{pwb}}+0.3 \mathrm{~T}_{\mathrm{a}}$ \\
& & & ${ }^{\circ} \mathrm{C}$ & $\mathrm{m} / \mathrm{s}$ & \\
& wave & & & $0.03<\mathrm{v} \leq 3$ & $\mathrm{WBGT}_{\mathrm{g}}+0.1 \mathrm{~T}_{\mathrm{a}}$ \\
& radiation & & & $\mathrm{m} / \mathrm{s}$ & $\left(\mathrm{T}_{\mathrm{a}}-\mathrm{T}_{\mathrm{pwb}}\right)$
\end{tabular}

\subsubsection{Spatial mapping and Annual Radiation Heat Stress}

355 The analysis space (i.e. office space) is framed with a grid of $0.5 \times 0.5 \mathrm{~m}$ on the floor plan. The significance of

356 the grid is to identify areas with the highest Annual Radiation Heat Stress (ARHS) percentage, where the manikin

357 is exposed to extreme heat stress conditions (see Figure 4).

358 In this study, a similar approach to the ARD index, which is introduced by Zani et al. (2019) [17], is based on the

359 WBGT variation (not $\triangle \mathrm{MRT}$ variation) and named ARHS, is adopted to assess extreme heat stress conditions.

360 The ARHS metric is defined as the percentage of the yearly-occupied hours when the $\Delta$ WBGT is positive for each 361 manikin position (i.e. WBGT above the threshold of $\mathrm{WBGT}_{\mathrm{ref}}$ ). To define the WGBT, which is the WBGT $\mathrm{WW}_{\mathrm{SW}}$ 362 the $\mathrm{WBGT}_{\mathrm{LW}}$, the script refers to the threshold of $4{ }^{\circ} \mathrm{C}$ (see eq. (10)). The $\mathrm{t}_{\mathrm{i}}$ is defined as each occupied hour in a 363 year $(\mathrm{h})$, and the $\mathrm{WBGT}_{\mathrm{i}}$ is the hourly value of wet bulb globe temperature $\left({ }^{\circ} \mathrm{C}\right)$ for each point of the grid that will

364 be compared with the threshold reference of WBGT for that specific hour.

$365 \quad$ ARHS $=\frac{\sum_{\mathrm{j}}\left(\mathrm{wf}_{\mathrm{i}} \cdot \mathrm{t}_{\mathrm{i}}\right)}{\sum_{\mathrm{j}} \mathrm{t}_{\mathrm{i}}} \quad \mathrm{wf}_{\mathrm{i}}=1$ if; $\mathrm{WBGT}_{\mathrm{i}}>\mathrm{WBGT}_{\mathrm{ref}}$ be used in the preliminary design stage by designers to show the distribution of the extreme heat stress conditions, which will be useful to assess different fenestration systems. 
369 Additionally, in order to compare the differences caused by the effect of distance from the façade and the level of 370 activity, it was decided to calculate the number of occupied discomfort hours, driven by solar radiation, that would

371 occur for each of the test conditions if $\triangle \mathrm{WBGT}>0$.

$372 \quad 3.2 \quad$ Description of the test case scenario

373 The model replicates the ASHRAE BESTEST Lightweight office space [33], as it is considered a reference for 374 indoor thermal comfort analysis. The model represents an office space, located in Milan (latitude $45.4642^{\circ} \mathrm{N}$, longitude $9.1900^{\circ} \mathrm{E}$ ), Italy. The dimensions of the office space are $8 \mathrm{~m}$ in width, $6 \mathrm{~m}$ in depth, and $3 \mathrm{~m}$ in height.

376 The south exposed façade holds two windows with dimensions of $2 \mathrm{~m} \times 3 \mathrm{~m}$ each (see Figure 4 ). The hourly annual weather data was selected for Milano Linate 160800 IGDG from the Energy Plus Weather (EPW) repository [34].

a

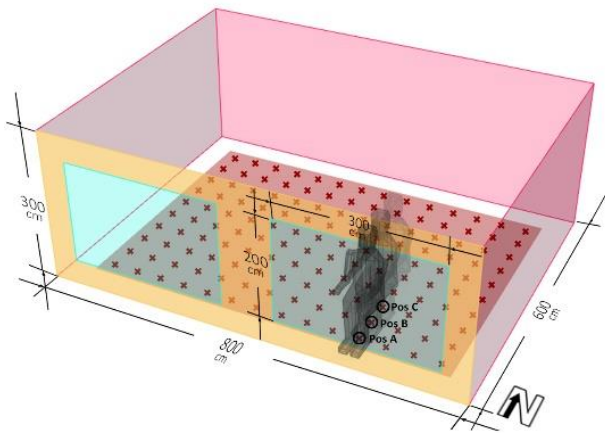

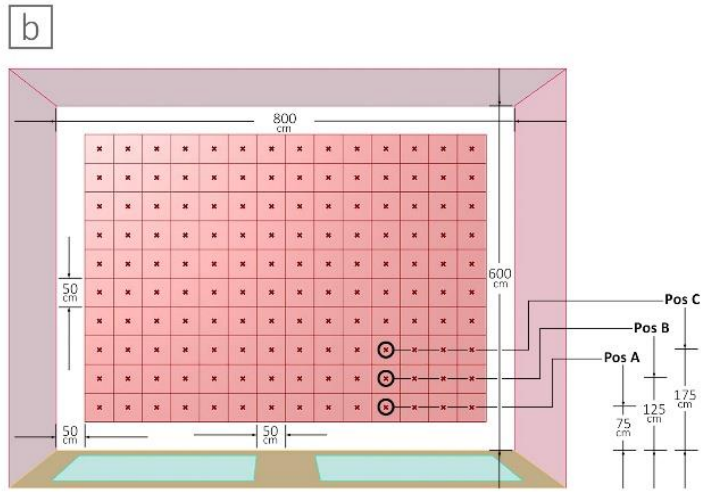

378

379 Figure 4 - a) Office space configuration with the analysis grid, and b) key plan with different positions of a manikin.

380 The thermal properties set for the elements composing the south-facing wall are listed in Table 5; all the other

381 surfaces are considered to be adiabatic.

Table 5 - Exterior wall construction elements properties.

\begin{tabular}{lccccc}
\hline Element & $\boldsymbol{\lambda}$ & $\mathbf{x}$ & $\mathbf{U}$ & $\boldsymbol{\rho}$ & $\mathbf{C}_{\mathbf{p}}$ \\
Unit & $\mathrm{W} / \mathrm{mK}$ & $\mathrm{m}$ & $\mathrm{W} / \mathrm{m}^{2} \mathrm{~K}$ & $\mathrm{~kg} / \mathrm{m}^{3}$ & $\mathrm{~J} / \mathrm{kgK}$ \\
\hline Internal Surface Coefficient & - & - & 8.290 & - & - \\
Plaster Board & 0.16 & 0.01 & 13.33 & 950 & 840 \\
& & & & & \\
Fiber Glass Quilt & 0.04 & 0.07 & 0.61 & 12 & 840 \\
& & & & & \\
Wood Siding & 0.14 & 0.01 & 15.56 & 530 & 900
\end{tabular}


Different alternatives are considered for the analysis in order to study the application of the WBGT approach for

384 this case study with different envelope configurations: (1) the insulated glazing unit (IGU) with a $\mathrm{T}_{\text {sol }}=0.60$ (T60),

385 (2) the solar control glass with a $\mathrm{T}_{\mathrm{sol}}=0.28$ (T28), (3) the standard IGU plus Roller Blind with 0.3 solar 386 transmittance overall $(\mathrm{T} 60+\mathrm{R})$. The first two alternatives, the T60 and the T28, do not present shading systems, 387 while the third alternative, the $\mathrm{T} 60+\mathrm{R}$, presents a dynamic shading system. The roller blind is simulated as a 388 translucent panel and it works according to the criteria defined with the sensor placed on the human body at the distance of $1.25 \mathrm{~m}$ from the window: if the $\Delta \mathrm{WBGT}>0$, the shading control is automatically on, otherwise, it is

390 off. Meanwhile, the thermal and radiative properties set for the window and construction elements are summarized in Table 6.

Table 6 - Thermal and radiative properties of different elements.

\begin{tabular}{|c|c|c|c|}
\hline Element & $\mathbf{U}\left(\mathrm{W} / \mathrm{m}^{2} \mathrm{~K}\right)$ & $\rho_{\mathrm{sol}}(-)$ & $\mathrm{T}_{\mathrm{sol}}(-)$ \\
\hline Exterior wall & 0.51 & 0.5 & - \\
\hline Floor & Adiabatic & 0.2 & - \\
\hline Ceiling & Adiabatic & 0.8 & - \\
\hline Interior wall & Adiabatic & 0.5 & - \\
\hline Glazing (1) & 1.40 & - & 0.60 \\
\hline Glazing (2) & 1.40 & - & 0.28 \\
\hline Shading & - & 0.6 & - \\
\hline
\end{tabular}

393 All the alternatives (T60, T28, and T60+R) are simulated by placing the manikin in three positions of $0.75 \mathrm{~m}$,

$3941.25 \mathrm{~m}$, and $1.75 \mathrm{~m}$ distant from the window in order to study the effect of the solar radiation on thermal comfort 395 related to the distance from the fenestration system.

396 According to the office use, internal load density is defined as equipment $\left(7 \mathrm{~W} / \mathrm{m}^{2}\right)$, lighting $\left(12 \mathrm{~W} / \mathrm{m}^{2}\right)$ and people $397\left(0.05\right.$ people $\left./ \mathrm{m}^{2}\right)$. The schedules of occupancy, equipment, and lighting are obtained accordingly from the default office schedules of Honeybee plug-in, taking into account 8:00 to 18:00 as working hours. 

with an ideal system with unlimited power able to instantaneously deliver the expected indoor thermal conditions.

401 For the simulation, it was assumed that all windows were closed, the amount of infiltration was set to low, $\sim 0.1$ each, and air speed was considered to be $0.1 \mathrm{~m} / \mathrm{s}$.

403 Different metabolic rates were considered, those classified as resting, low metabolic rate, moderate metabolic rate and high metabolic rate. The $\mathrm{M}$ values were assigned according to the values listed in Table 1 . These values were used for simulations of the occupied discomfort hours percentage, driven by solar radiation, to find the trend of this percentage against different metabolic rate values (increasing from very low to high metabolic rate). For the standard simulation, a low metabolic rate (e.g., $180 \mathrm{~W}$ ) was set based on the office space. To calculate hourly shortwave $\Delta \mathrm{MRT}$, the shortwave absorptivity was fixed for $\propto_{\mathrm{sw}}=0.67$ (approximated value for white skin and average clothing). Likewise, the longwave absorptivity $\propto_{\mathrm{LW}}$ of the human body was set to be approximately 0.95 . The fraction of body surface exposed to radiation $\mathrm{f}_{\text {eff }}$ was set to be 0.696 (seated), $\mathrm{h}_{\mathrm{r}}$ is the radiation heat transfer coefficient, which was assumed to be equal to $6.012 \mathrm{~W} / \mathrm{m}^{2} \mathrm{~K}$, and the orientation of the manikins were toward the south. Finally, to compute WBGT, it was assumed that the office workers were always non-acclimatized in order to aim for the most unfavorable indoor thermal perception.

414 A comparative analysis was also performed for three specific days to better understand the effect of solar radiation on Adjusted MRT and WBGT (Section 4.4). The analysis was performed for the $1^{\text {st }}$ to the $3^{\text {rd }}$ of September, considering the maximum incident radiation (in Milan) that is on the $2^{\text {nd }}$ of September at 11:00; this allowed monitoring of the trend of Adjusted MRT and WBGT with the presence of the incident solar radiation. These three days were selected to examine the sensitivity of WBGT, Adjusted MRT, and PMV, with the peak value of the incident solar radiation and to better study them for the largest solar radiation changes during these three days.

\section{Results and discussion}

421 The results from the simulations are broken down into five sections and represent examples of the typical outcomes obtained following the presented methodology. In Section 4.1, the annual analysis of indoor thermal comfort is presented. Section 4.2 presents the results of the occupied discomfort hours percentage, driven by solar radiation. Then, Section 4.3 explains the results of the ARHS metric. In Section 4.4, a comparison between

$425 \Delta$ WBGT and Adjusted PMV is presented. In this section, detailed analysis for three days is also introduced to better study and interpret the presence of the solar radiation on the Adjusted MRT and WBGT. Section 4.5 presents

427 the point-in-time values of predicted $\triangle \mathrm{WBGT}$ and Adjusted PMV from the simulations. This part of the study 
allows comparison of the results of the here presented approach with the outcome of the traditional thermal comfort model. It should be noted that all different sections of the outcomes are presented to show the potential of applying the proposed method under a variety of settings.

\subsection{Annual analysis of indoor thermal comfort}

432

In this section, annual heat maps of $\triangle \mathrm{MRT}, \triangle \mathrm{WBGT}$, and PMV are presented. Figure 5 shows the simulation results for T60 glazing with an occupant seated $0.75 \mathrm{~m}$ away from the window and facing the glazed surface. By considering the annual heat map of $\triangle \mathrm{MRT}$ (see Figure 5a), large variations are found (values between $0{ }^{\circ} \mathrm{C}$ to 25 $\left.{ }^{\circ} \mathrm{C}\right)$. By comparing annual heat maps of $\triangle \mathrm{MRT}$ and $\triangle \mathrm{WBGT}$, it is evident that the latter highlights only severe heat stress conditions (see Figure 5a and c). This approach estimates the hourly WBGT values and compares them to the $\mathrm{WBGT}_{\text {ref }}$ values, considering the correct metabolic rates, to find the heat stress conditions.

The annual map of the Adjusted PMV (Figure 5b) includes black dashed line patterns representing the conditions when Adjusted PMV values exceed the maximum validity range of the PMV scale $(>+3)$. This means that it is certain that a heat stress condition is present, but the graph does not communicate this condition accurately because it neglects the criticality of the condition. Annual heat maps of Adjusted PMV and $\triangle$ WBGT give the possibility of preliminary comparison by qualitative means. WBGT provides a good estimation of the intensity of thermal heat stress through the color gradient used by revealing: (i) a less sensitive scale than PMV, (ii) a reduction of possible discomfort hours, and (iii) the capability of user adaptation.

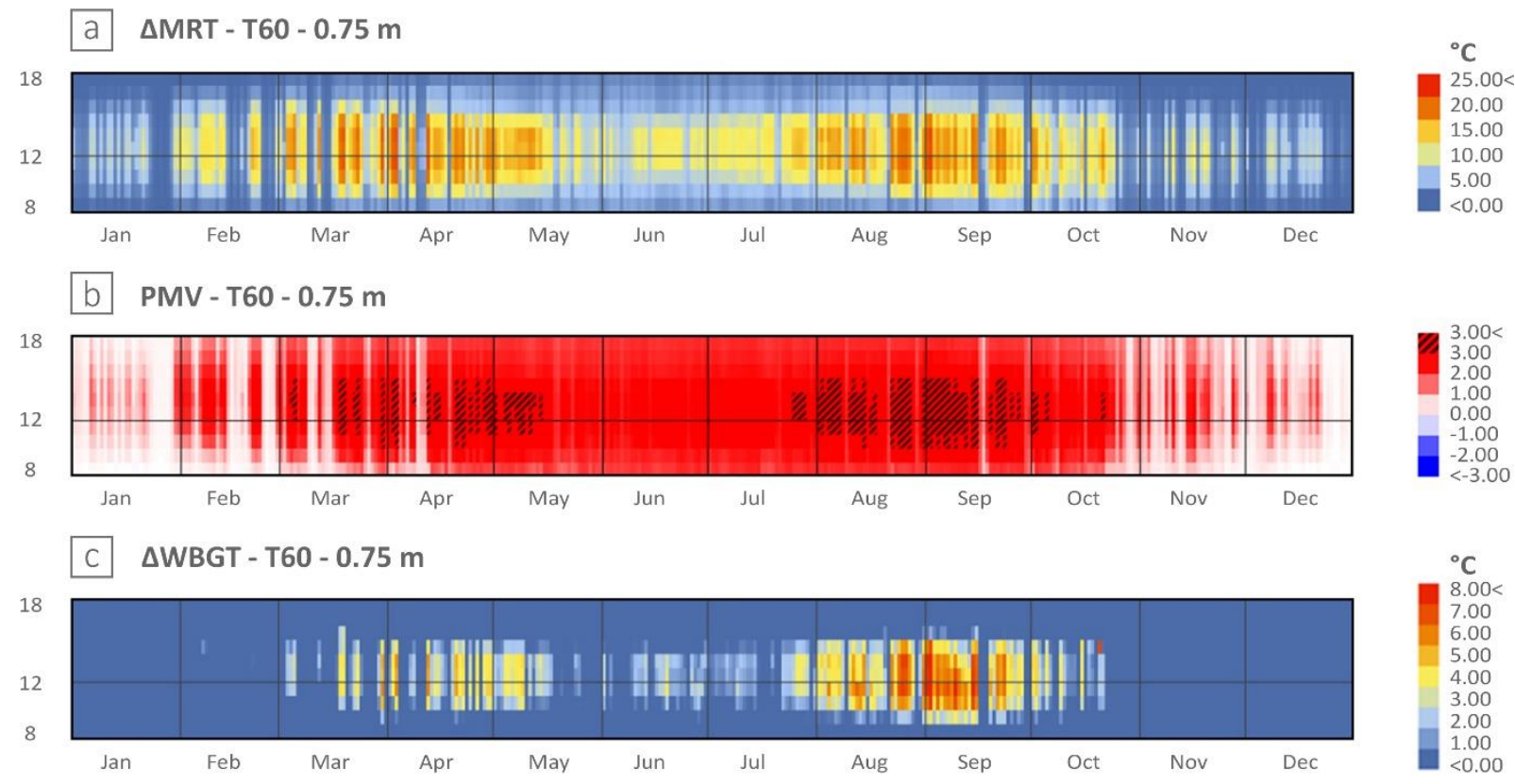


447 For the sake of comparison, additional results are presented. Figure 6 shows the results of three indices of $\Delta \mathrm{MRT}$,

$448 \quad$ PMV and $\triangle \mathrm{WBGT}$ for T28 glazing with an occupant seated $0.75 \mathrm{~m}$ away from the window and facing the glazed

449 surface. Smaller variations in the annual heat map of $\triangle M R T$ (see Figure 6a) were found for this scenario compared 450 to the T60 glazing scenario (see Figure 5a). The Figure 6b shows that Adjusted PMV values were between zero 451 and three during working hours for the whole year. The $\triangle$ WBGT value was constantly zero, meaning that hourly 452 WBGT value did not surpass the $\mathrm{WBGT}_{\text {ref }}$ value all along the year (see Figure 6c). As the PMV, the WBGT is 453 sensitive to the solar transmittance of the glazing, when estimating thermal discomfort in the indoor office environment. By comparing the PMV outcomes between the scenarios T60 and T28, the glazing with lower solar transmittance value did not show values outside the maximum threshold of the PMV (see Figure 5b and 6b). The $\Delta$ WGBT maps (Figure 5c and 6c) assert that risk of heat stress was avoided in the T28 scenario, while the extreme heat stress conditions (intensity and period) were highlighted in the T60 scenario due to the glazing used .

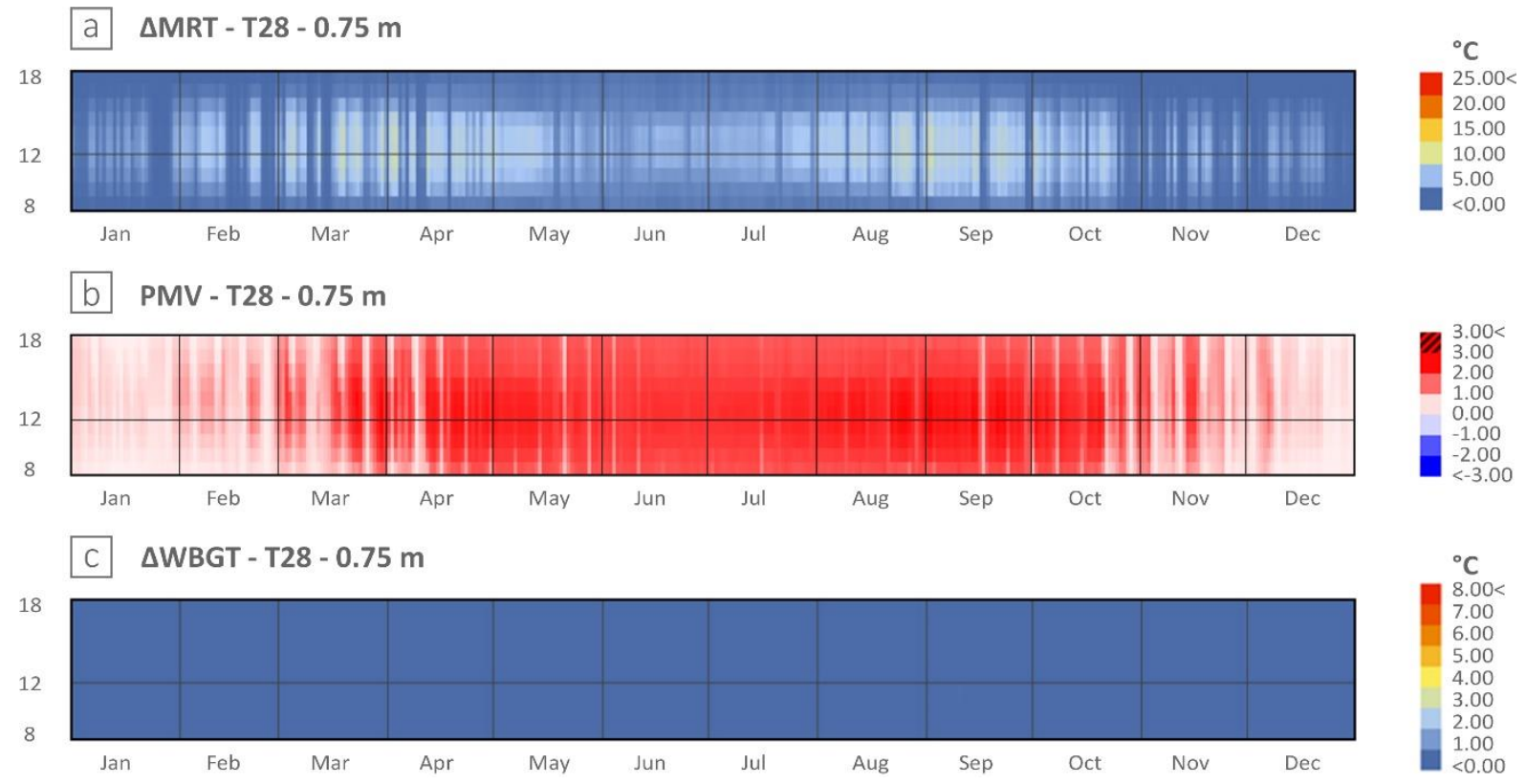

Figure 6 - Annual heat maps for T28, $0.75 \mathrm{~m}$ from the façade: a) $\triangle M R T$, b) PMV, and c) $\triangle W B G T$.

As it was found in the preliminary investigations described in Section 2.2, using the CBE Thermal Comfort Tool, the PMV value considering direct solar radiation can be above the maximum value of the thermal comfort scale $(>+3)$. The comparison of the annual heat maps of Adjusted PMV and $\triangle \mathrm{WBGT}$ presented in this section highlights that when the PMV exceeds the maximum range of the model in an extreme condition (see Figure 5b), it cannot well represent how warm the condition is perceived by the occupants. On the other hand, the WBGT approach can be seen as a better option, given that it is not only a less sensitive index, but also provides a good estimation of the heat stress condition taking into account the effect of the solar radiation. 
468 The occupied discomfort hours percentage, driven by the presence of the solar radiation, for different glazing 469 types (T60 and T28), occupant positions ( $0.75 \mathrm{~m}, 1.25 \mathrm{~m}$, and $1.75 \mathrm{~m}$ away from the window) and metabolic 470 rates are compared in Figure 7a (during the working hours). This percentage was calculated in accordance with 471 the value of WBGT that surpasses the limit boundaries of $\mathrm{WBGT}_{\text {ref, }}$ for each of the assumed metabolic rates.

472 Figure 7a summarizes the findings by counting the annual hourly conditions of heat stress for the scenarios T28 473 and T60 (figures 7b, c, and d). By assuming an increased level of activity from very low (e.g., resting with M=115

$474 \mathrm{~W}$ ) to very high activity (e.g., exercising with $\mathrm{M}=415 \mathrm{~W}$ ), the risk of heat stress also rises. Since the body produces 475 more heat internally, it experiences a higher body core temperature. For the scenario T60 at $0.75 \mathrm{~m}$ away from 476 the window, the difference between the occupied discomfort hours percentage driven by solar radiation for a very 477 low and very high level of activity inside the space was $35.0 \%$. Due to the presence of direct solar radiation, there 478 was a strong link between the perceived discomfort conditions and the transmittance of the glazing system. In the 479 case of T28 at $0.75 \mathrm{~m}$ away from the window, the difference between the occupied discomfort hours percentage 480 driven by solar radiation between a very low and very high level of activity was halved and decreased to $17.0 \%$.

481 Figures $7 \mathrm{~b}$, c, and d present the annual distribution of WBGT for three different positions $0.75 \mathrm{~m}, 1.25 \mathrm{~m}$, and $4821.75 \mathrm{~m}$ from the window for the scenario T60. Moving away from the window from $0.75 \mathrm{~m}$ to $1.75 \mathrm{~m}$, a reduction 483 of the calculated WBGT values that are positioned above the $\mathrm{WBGT}_{\text {ref }}$ can be seen. For the scenario T60, $1.75 \mathrm{~m}$ 484 away from the window, the general trend established was that from winter to summer, the values of WBGT were 485 rising from $10{ }^{\circ} \mathrm{C}$ until $31{ }^{\circ} \mathrm{C}$. This means that there was no condition above WBGT ref lines of $115 \mathrm{~W}$, and 486 consequently, the occupied discomfort hours percentage, driven by solar radiation, for this metabolic rate was 487 zero. In winter, due to the lower altitude of the sun, the manikin (for both $0.75 \mathrm{~m}$ and $1.25 \mathrm{~m}$ from the window) 488 received a greater amount of solar radiation. Whereas in summer, due to the higher altitude of the sun; only the 489 area near the façade ( $0.75 \mathrm{~m}$ from the window) received a high amount of solar radiation. This does not mean that 490 the manikin far from the window $(1.75 \mathrm{~m})$ did not represent a thermal discomfort condition, but it implies that the 491 influence of direct solar radiation was reduced compared to the manikin closer to the window (0.75 $\mathrm{m})$ and, the 492 heat stress condition still can occur depending on other factors, (e.g., metabolic rate), defining the $\mathrm{WBGT}_{\text {ref }} \mathrm{Value}$ 

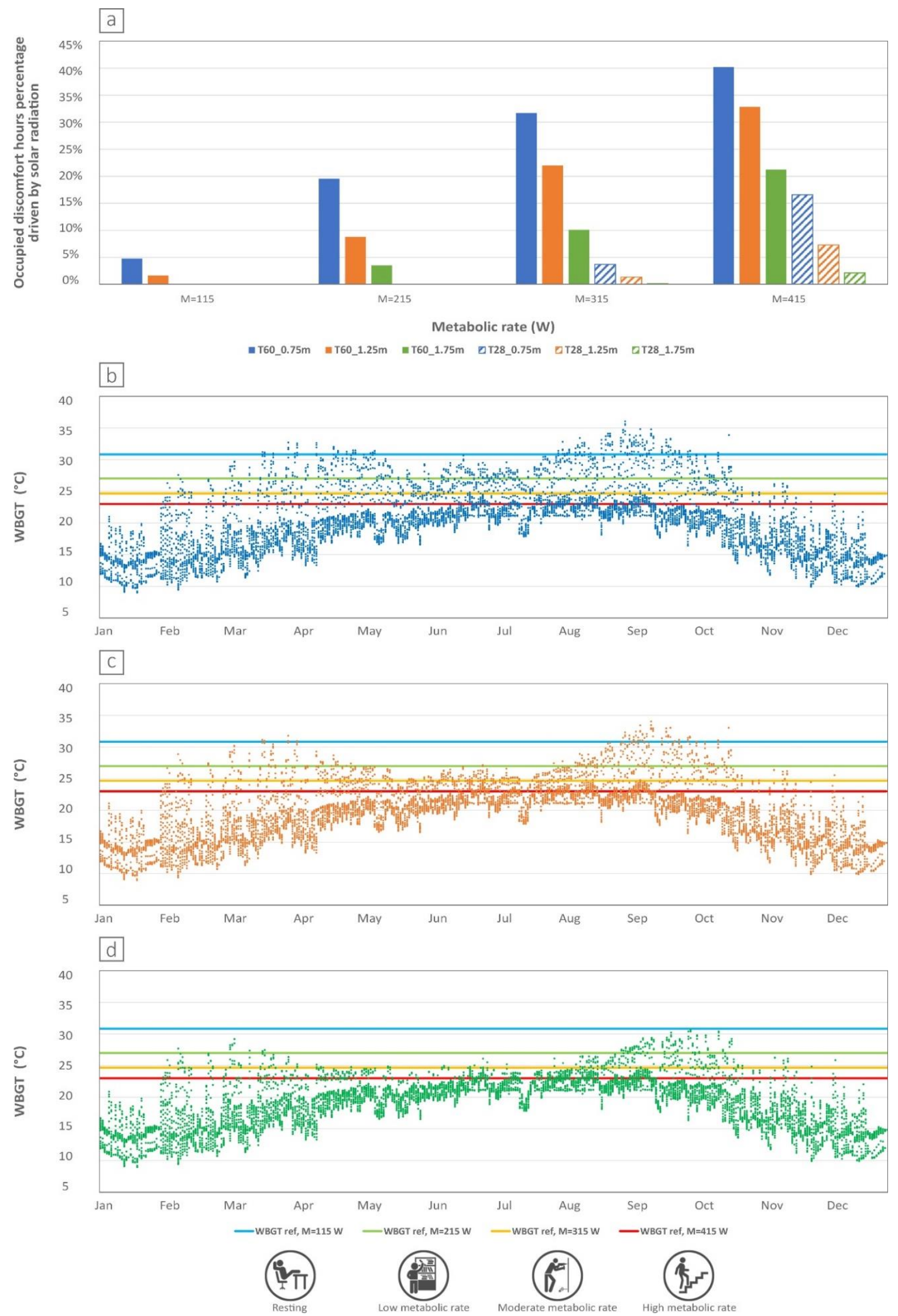

494 Figure 7 - a) Occupied discomfort hours percentage, driven by solar radiation, and variation of WBGT during the year for 495 T60: b) $0.75 \mathrm{~m}, \mathrm{c}) 1.25 \mathrm{~m}$, and $d) 1.75 \mathrm{~m}$ from the window. 


\subsection{Annual Radiation Heat Stress}

497 An example of a spatial map distribution of ARHS is hereby reported and is useful if it is based on the separation

498 of manikins. This map shows the percentage of occupied discomfort hours; that is, where the $\Delta$ WBGT is greater

499 than $0{ }^{\circ} \mathrm{C}$. This map was created considering an increase in $\triangle$ WBGT (e.g., $1^{\circ} \mathrm{C}$ ) which corresponds to heat stress,

500 under some particular condition (e.g. air temperature, metabolic rate), but it does not give an idea of the magnitude.

501 Figure 8 shows the false-color plots of ARHS Autonomy for two different iterations, one without shading (T60)

502 and the other considering a movable roller-shade (T60+R) for typical working hours in Milan (8:00-18:00).

503
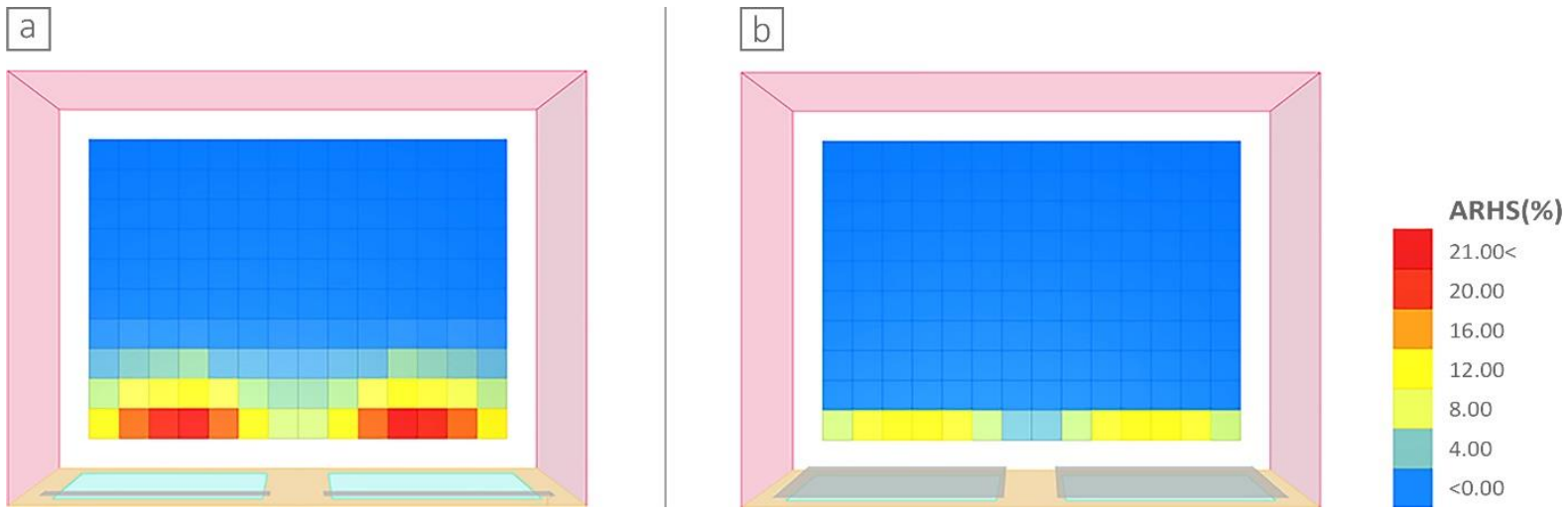

504

Figure 8 - False color plots of Annual Radiation Heat Stress with glazing a) T60, and b) T60+R.

505 The application of dynamic shading for the case of T60+R was made according to the criteria defined with the representative sensor (placed on the human body) at the distance of $1.25 \mathrm{~m}$ from the window and as described in

507 the methodology chapter.

508 Due to the control strategy applied for the cases of T60+R (Figure 8b), lower annual radiation heat stress

509 percentages were observed near the window than in the case of T60. It is visible from the plots for the case of

$510 \mathrm{~T} 60+\mathrm{R}$ that there is no area with ARHS $>12 \%$ because of the lower frequency of heat stress compared to the case

511 of T60. Thus, the case of T60+R had a more favorable performance in terms of heat stress caused by solar radiation

512 and a more flexible furniture plan for designing the interior space.

513 The metric of ARHS calculated using $\triangle$ WBGT can be a useful index for architects and designers to compare

514 different fenestration systems, especially in the preliminary design stage, to reduce the effect of the incoming

515 shortwave solar radiation. In a more holistic and detailed analysis, it can integrate in both daylight and energy

516 simulations to address the trade-offs between all thermal and visual aspects for designing a more appropriate

517 building envelope and shading devices systems. 


\section{$518 \quad 4.4$ Comparative analysis of indoor thermal comfort}

519 A comparative analysis was performed for the $1^{\text {st }}$ to the $3^{\text {rd }}$ of September to better understand the effect of the 520 solar radiation on Adjusted MRT and WBGT. The choice of the three days was made following the distribution 521 of the change in the WBGT presented in Figure 7, in which can be seen a peak in heat stress due to the coupled 522 effects of temperature, solar radiation intensity, and solar altitude (and related solar access). Significant variations 523 on the WBGT were found, with a considerable hourly fluctuation of the value during the day, and in particular at 524 midday. The maximum value of Adjusted MRT for this period was $51^{\circ} \mathrm{C}$, while the value of WBGT reached up

525 to $32{ }^{\circ} \mathrm{C}$, coupled both with an indoor air temperature equal to $26^{\circ} \mathrm{C}$ (considering the distance of $1.25 \mathrm{~m}$ from the 526 window). As expected, in Figure 9 it is shown that the value of Adjusted MRT was often higher than the MRT.

527 For example, on the $2^{\text {nd }}$ of September at 12:00, $\Delta \mathrm{MRT}$ reached $17^{\circ} \mathrm{C}$ (Figure $9 \mathrm{a}$ and $\mathrm{b}$ ).

528 Figure 9c also compares the hourly values of Adjusted PMV (including the intensity of the shortwave solar 529 radiation on the occupant) with $\triangle \mathrm{WBGT}$ for the case of T60, for different positions away from the window for 530 the selected analysis period. For the worst condition (i.e. the $2^{\text {nd }}$ of September at 15:00, for the case of $0.75 \mathrm{~m}$ away 531 from the window), the Adjusted PMV reached a +4 thermal sensation scale, which exceeded the limits of its 532 standard seven-point scale, while the WBGT remained under the maximum limit (Figure 3). Consequently, the 533 WBGT was within the boundary thresholds, while the Adjusted PMV was not. The Bernard and Liljegren tags on 534 the horizontal axis of Figure 9c show the period that each of the methods was used to estimate the hourly WBGT 535 value, which is compared with the $\mathrm{WBGT}_{\text {ref }}$ for calculating $\triangle \mathrm{WBGT}$. For instance, the Liljegren methodology 536 was used with the presence of solar irradiance during midday, while there are conditions that the Bernard method 537 was implemented due to the absence of the solar irradiance. 


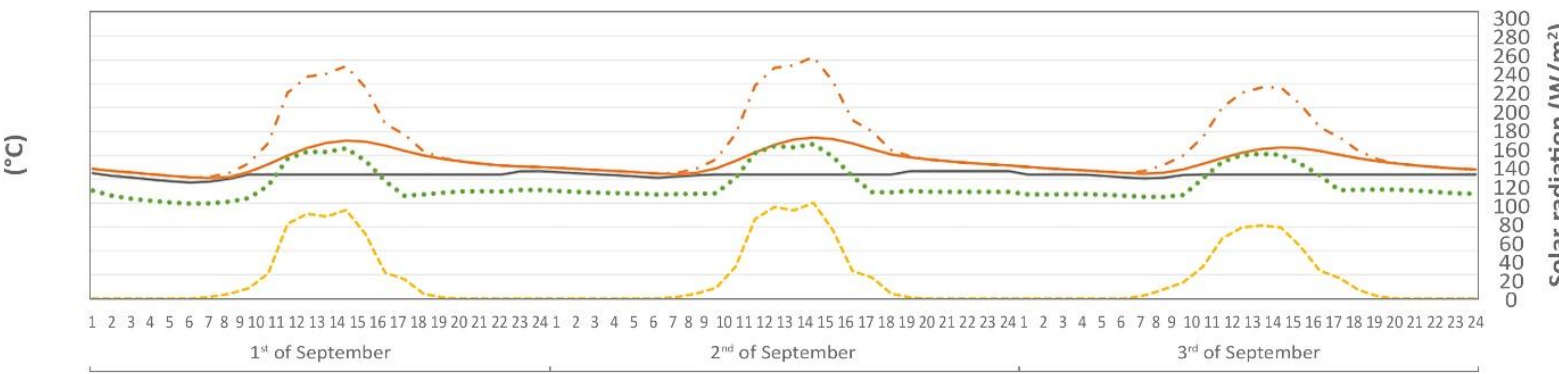

$\mathrm{b}$

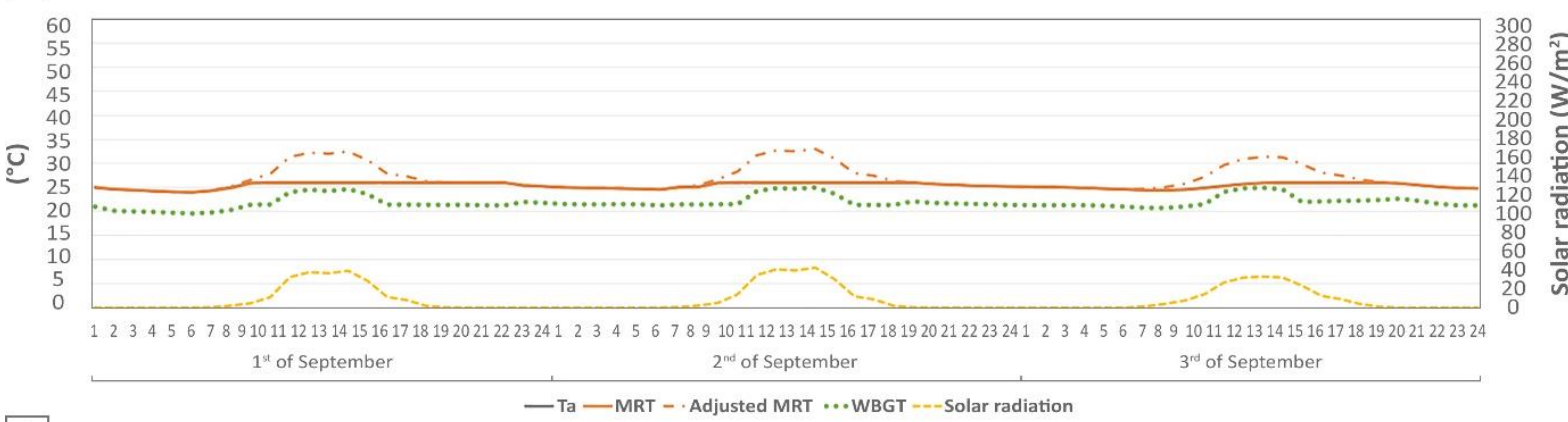

C

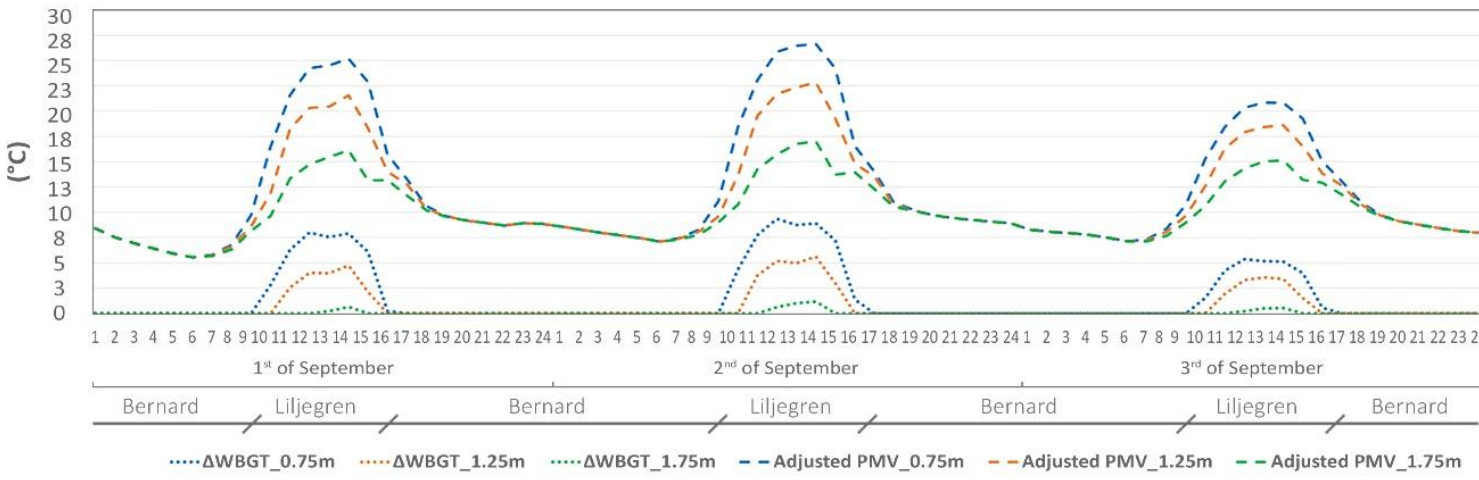

Figure 9 - a) Comparative analysis of air temperature, MRT, Adjusted MRT, WBGT, and Solar radiation from the $1^{\text {st }}$ to the

$3^{\text {rd }}$ of September, $1.25 \mathrm{~m}$ from the window for T60, b) comparative analysis of air temperature, MRT, Adjusted MRT, WBGT,

541 and Solar radiation from the $1^{\text {st }}$ to the $3^{\text {rd }}$ of September, $1.25 \mathrm{~m}$ from the window for T28, and c) the effect of user distance

542 from the façade on $\triangle W B G T$ and Adjusted PMV from the $1^{\text {st }}$ to the $3^{\text {rd }}$ of September, for T60.

543 The detailed hourly results presented in this section show that the WBGT, such as Adjusted PMV, is sensitive to

544 the position of occupant and the material's properties of the building envelope, especially the solar transmittance

545 value of the glazing, and can be used to estimate the dissatisfaction in the indoor office environment.

546 Comparative analysis of indoor thermal comfort proves that the Adjusted PMV value could be higher than the

547 maximum acceptable value of PMV for some extreme conditions. However, given that it is a less sensitive index

548 to huge solar radiation change, the heat stress index of WBGT can be seen as a better option to assess the direct 
550 for assessing the discomfort is reduced using this approach, but the peak intensity is overlapping for both $\triangle$ WBGT

551 and Adjusted PMV, and the resulting values are out of the validity limit of the formula.

552 It should be noted that the heat stress approach does not express the general comfort condition of occupants inside

553 the space. As an aim of this study was the assessment of the presence of the direct solar radiation effect, it has

554 been considered only for the dissatisfaction mostly caused by shortwave solar radiation. However, further 555 improvements are needed to take the thermal comfort hours and their overlapping with heat stress hours into

556 account in the design stage. These developments will help to inform the design process and provide designers

557 with better insight for improving the performance of building envelope leading to the creating of office

558 environments that are more thermally comfortable and positively affect the occupants' productivity.

\section{$559 \quad 4.5$ Point-in-time predicted $\triangle$ WBGT and Adjusted PMV}

560 This last section of results is presented to highlight the differences between predicted $\Delta$ WBGT and Adjusted PMV

561 considering several point-in-time simulation results. Table 7 gives the prediction of WBGT and $\triangle$ WBGT values

562 corresponding to particular combinations of the parameters (e.g. ERF, relative humidity, air temperature, MRT,

563 Adjusted MRT). These results are presented considering $0.1 \mathrm{~m} / \mathrm{s}$ as air speed, $180 \mathrm{~W}$ (1.7 met) as metabolic rate 564 and 0.6 clo as clothing level.

Table 7 - Examples of prediction of WBGT, $\triangle W B G T$, and Adjusted PMV from the simulations.

\begin{tabular}{|c|c|c|c|c|c|c|c|c|c|}
\hline Condition & $\begin{array}{c}\text { ERF } \\
\left(\mathrm{W} / \mathrm{m}^{2}\right)\end{array}$ & $\begin{array}{l}\text { RH } \\
(\%)\end{array}$ & $\begin{array}{c}\mathbf{T}_{\mathbf{a}} \\
\left({ }^{\circ} \mathrm{C}\right)\end{array}$ & $\begin{array}{l}\text { MRT } \\
\left({ }^{\circ} \mathrm{C}\right)\end{array}$ & $\begin{array}{c}\Delta \text { MRT } \\
\left({ }^{\circ} \mathrm{C}\right)\end{array}$ & $\begin{array}{c}\text { Adjusted MRT } \\
\left({ }^{\circ} \mathrm{C}\right)\end{array}$ & $\begin{array}{c}\text { WBGT } \\
\left({ }^{\circ} \mathrm{C}\right)\end{array}$ & $\begin{array}{c}\text { WWBGT } \\
\left({ }^{\circ} \mathrm{C}\right)\end{array}$ & Adjusted PMV \\
\hline (1) & 28.3 & 30.4 & 21.6 & 21.0 & 6.8 & 27.8 & 18.8 & 0.0 & 0.1 \\
\hline (2) & 57.0 & 21.3 & 26.0 & 26.0 & 13.7 & 39.7 & 25.4 & 0.0 & 1.6 \\
\hline (3) & 89.0 & 39.3 & 26.0 & 31.0 & 21.3 & 52.3 & 31.1 & 3.0 & 3.3 \\
\hline (4) & 94.0 & 55.0 & 26.0 & 32.7 & 22.5 & 55.2 & 35.6 & 7.5 & 4.0 \\
\hline
\end{tabular}

566 Table 7 presents multiple examples of point-in-time values from the results of the simulation. Conditions (1) and

567 (2) are presented for the combinations of parameters that yield values of 0.1 and 1.6 on the thermal sensation

568 scale, respectively. The prediction of the WBGT heat stress model for these conditions was zero due to low

569 incident solar radiation combined with other parameters. 
570 The outcomes of the traditional PMV model considering the Adjusted MRT values of $52.3^{\circ} \mathrm{C}$ condition (3) was

5713.3 on the thermal sensation scale $(\mathrm{PMV}>+3)$. This condition shows that for this point-in-time, the PMV model

572 was unable to express how much heat iin this condition was caused by the $89.0 \mathrm{~W} / \mathrm{m}^{2}$ ERF value, with $52.3^{\circ} \mathrm{C}$

573 Adjusted MRT. With reference to the traditional PMV model, it is not possible to interpret the difference between

5743.3 for condition (3) and 4.0 for condition (4) in terms of thermal sensation scale. It should be noted that the

575 WBGT $>31.1$ is almost equal to PMV $>+3$ : this implies to have missing information about the magnitude of the 576 heat stress.

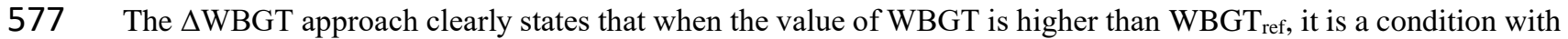
578 heat stress (e.g., $\triangle \mathrm{WBGT}$ value of $3.0^{\circ} \mathrm{C}$ for the conditions (3)); otherwise, there is no heat stress (e.g., $\Delta \mathrm{WBGT}$ 579 value of zero for the conditions (1) and (2)).

580 The PMV model predicts the thermal comfort condition of occupants with the ASHRAE seven-point thermal sensation scale (cold, cool, slightly cool, neutral, slightly warm, warm, and hot), and as long as incident solar

582 radiation is low or absent, this prediction can be reasonable. However, its value falls out of scale in the presence of shortwave solar radiation (extreme events). Moreover, human beings are not always able to perceive the heat stress, nor the changes. The alternative method of WBGT is pretty similar to the PMV model, where there is the presence of shortwave solar radiation effects. However, the WBGT has the capability to consider the user adaptation by reducing the number of conditions perceived as a heat stress.

587 The heat stress approach of WBGT does not classify the thermal comfort conditions as neutral, slightly warm,

588 etc., but identifies the heat stress based on the pre-defined threshold and further quantifies this heat stress with a WBGT value. From this perspective, the use of WBGT, which makes the heat stress determination less sensitive to solar radiation values and reduces out of scale values, is preferable for the purpose of evaluating the effect of solar radiation on indoor thermal comfort.

\section{Limitations of the study}

This section presents some limitations of this study that might encourage future developments. Firstly, the air speed inside the indoor environment was considered constant, given that the focus of this study was to demonstrate the application of the WBGT approach in assessing the direct solar radiation effect on indoor thermal comfort. heat stress conditions. 
598 Secondly, the reflected radiation from the surrounding surfaces (e.g., walls, ceiling and floor) has already been 599 assessed by means of the simulation procedure, enabled by the Radiance - DC method, estimating the amount of 600 irradiation directly falling on the manikin and the amount of reflected portion from the rooms' surfaces toward 601 the manikin. A standard office, with average surface solar reflectances for the surfaces, was proposed in this study.

602 Further dedicated analysis should be conducted to quote specifically how the change in reflectance of each internal 603 surface, or the average reflectance of the room surfaces can affect the thermal comfort perceived by the user.

604 Thirdly, in relation to the Radiance - DC method, the modeled geometry and manikin considered do not include 605 a desk as a working plane for the occupant, which would represent an immediate shading source, thereby changing 606 the total solar radiation falling on the occupant, and the re-reflected component of solar radiation might also 607 increase the intensity of total solar radiation. Adding desks to the analysis scene would allow thorough and precise 608 calculation of the solar radiation landing on the human body could be reached. In this way, all the critical aspects, 609 from the overshadowing effect to solar reflections, could be considered. However, furniture surfaces are mostly 610 unknown to the designer.

611 Fourthly, the value of $\mathrm{f}_{\text {eff }}$ (which in the standardized calculation includes overshadowing effects and the effect of 612 clothing for incident solar radiation reduction) can lead to a change in $\triangle \mathrm{MRT}$ of up to $30 \%$. The exposure may be 613 different depending on the way the manikin is placed, but it is an approximation. It should be mentioned that this 614 assumption does not directly affect the WBGT and $\triangle$ WBGT results (change in WBGT up to 5\%). More in-depth 615 analysis is needed in subsequent work to take into account this limitation.

616 Fifthly, regarding the WBGT heat stress approach, it does not express the general comfort condition of occupants 617 inside an indoor space. Consequently, in order to better understand the thermal comfort together with the heat 618 stress conditions, an integrated approach can be developed in the future. The approach allows an overall insight 619 on how the designers' decisions directly affect the building envelope choices toward the definition of high620 performance office environments.

621 Finally, the WBGT calculation has several steps. Hence, future work can foresee a user-friendly software to be 622 used in the preliminary design stage by the architects and designers. Moreover, this WBGT methodology will be 623 potentially applicable as a heat stress index for both indoor and outdoor conditions. Consequently, it can be used 624 with a similar procedure to assess outdoor comfort in a future study.

\section{Conclusions}


626 This research introduces a framework to assess the effect of incoming shortwave solar radiation on indoor thermal

627 comfort and estimates the perceived thermal stress of the occupants. The novelty of this study is that it

628 demonstrates the implementation of the WBGT heat stress index for indoor thermal comfort through the

629 evaluation of the effect of solar radiation using the Radiance - DC method on the Grasshopper platform. This

630 framework is used to assess the discomfort hours due to shortwave solar radiation landing directly on occupants

631 considering it as heat stress by computing the $\triangle \mathrm{WBGT}$. To do so, two procedures are available to compute the

632 WBGT: the equation proposed by Bernard, which is used to assess the effects of longwave solar radiation, and

633 Liljegren's equations, which account for long and shortwave radiation. The results show the potential of applying

634 the proposed method under a variety of settings. For instance, the Liljegren methodology can be used with the

635 presence of solar irradiance during midday, while there are conditions with an absence of solar irradiance for

636 which the Bernard method can be implemented .

637 The PMV is the most widely used thermal comfort perception index. The way that the laboratory tests are carried

638 out and make it particularly sensitive when the person is exposed to direct solar radiation. The values that fall out

639 of the scale are not able to express the perceived heat stress properly. The WBGT has been tested as an alternative,

640 and the methodology is preferred, being less sensitive to huge solar radiation changes, reducing the out of scale

641 values, and limiting their expression of intensity.

642 The ARHS metric is similar to the ARD index, but it is based on the WBGT approach. The ARHS metric uses

643 WBGT to soften the sensitivity. It is applicable either indoor or outdoor, and it is flexible for rapid calculation on

644 spatial analysis. The spatial heat stress conditions across the indoor space can be assessed and compared for

645 different fenestration systems to reduce the effect of incoming shortwave solar radiation.

646 The detailed WBGT approach is potentially applicable for indoor environments under a variety of conditions, as

647 it was already reported in the literature for indoor thermal comfort. However, this study stresses this approach by

648 introducing a Delta Value approach that is based on Radiance - DC method. The proposed approach allows

649 designers, architects, and energy modelers to predict the heat stress of occupants across the area for every hour of

650 the year. The solar radiation can have an impact on the user's thermal perception onto a warmer condition, which can cause a comfortable or an uncomfortable state depending on the combination of indoor environmental

652 parameters. Even though the direct solar radiation landing on the occupant may occur only a few hours a day, it can also be reflected from the surroundings and can significantly change the perception of the occupant (see Figure

654 9). The excess heat produced by shortwave solar radiation cannot be compensated for a standard HVAC system, depending on air velocity, air temperature, and air-outlets location. This may modify and, most probably, increase 


\section{References}

660 [1] ASHRAE, Handbook of Fundamentals. 2013.

661 [2] Y. Al Horr, M. Arif, A. Kaushik, A. Mazroei, M. Katafygiotou, and E. Elsarrag, "Occupant productivity 662 and office indoor environment quality: A review of the literature," Build. Environ., vol. 105, pp. 369-389, 2016.

664 [3] M. B. C. Aries, J. A. Veitch, and G. R. Newsham, "Windows, view, and office characteristics predict physical and psychological discomfort," J. Environ. Psychol., vol. 30, pp. 533-541, 2010.

667

[5] K. Ceria and R. De Dear, "Thermal comfort and behavioural strategies in office buildings located in a

669

$670 \quad[6]$ hot-arid climate," J. Therm. Biol., vol. 26, pp. 409-414, 2001. P. O. Fanger, Thermal comfort. Analysis and applications in environmental engineering. 1970.

[8] S. I. H. Gilani, M. H. Khan, and W. Pao, "Thermal comfort analysis of PMV model Prediction in Air BSI, "BS EN ISO 7730: 2005 - Ergonomics of the thermal environment-Analytical determination and

[11] F. Bauman and E. Arens, "Task / Ambient Conditioning Systems: Engineering and Application

[12] E. Arens, T. Hoyt, X. Zhou, L. Huang, H. Zhang, and S. Schiavon, "Modeling the comfort effects of short-

[13] C. Marino, A. Nucara, M. Pietrafesa, and E. Polimeni, "The effect of the short wave radiation and its

[14] A. Zani, A. G. Mainini, J. D. B. Cadena, S. Schiavon, and E. Arens, "A New Modeling Approach for the 410, 2009.

[16] C. Huizenga, Z. Hui, and E. Arens, "A model of human physiology and comfort for assessing complex 
thermal environments," Build. Environ., vol. 36, no. 6, pp. 691-699, 2001.

[17] A. Zani, H. David Richardson, A. Tono, S. Schiavon, and E. Arens, "A simulation-based design analysis for the assessment of indoor comfort under the effect of solar radiation," in SimAUD, 2019, pp. 135-142.

[18] S. Carlucci, F. Causone, F. De Rosa, and L. Pagliano, “A review of indices for assessing visual comfort with a view to their use in optimization processes to support building integrated design," Renew. Sustain. Energy Rev., vol. 47, pp. 1016-1033, 2015.

[19] A. Beizaee, K. Vadodaria, and D. Loveday, "Assessing the ability of PMV model in predicting thermal sensation in naturally ventilated buildings in UK," in 7th Windsor Conference: The changing context of comfort in an unpredictable world, 2012.

[20] S. Schiavon, T. Hoyt, and A. Piccioli, "Web application for thermal comfort visualization and calculation according to ASHRAE Standard 55,” Build. Simul., vol. 7, pp. 321-334, 2014.

[21] T. Hoyt, S. Schiavon, A. Piccioli, T. Cheung, D. M. And, and K. Steinfeld, "CBE Thermal Comfort Tool.” 2017.

[22] E. Naboni, E. Danzo, and L. Ofria, “A Parametric Workflow to Concieve Facades as Indoor and Outdoor Climate," in SimAUD, 2019.

[23] F. R. d'Ambrosio Alfano, B. I. Palella, and G. Riccio, “Thermal Environment Assessment Reliability Using Temperature - Humidity Indices,” Ind. Health, vol. 49, 2011.

[24] Z. Zamanian, Z. Sedaghat, M. Hemehrezaee, and F. Khajehnasiri, "Evaluation of environmental heat stress on physiological parameters," J. Environ. Heal. Sci. Eng., vol. 15, pp. 1-8, 2017.

[25] K. Blazejczyk, Y. Epstein, G. Jendritzky, H. Staiger, and B. Tinz, "Comparison of UTCI to selected thermal indices," Int. J. Biometeorol., vol. 56, pp. 515-535, 2012.

[26] R. McNeel, “Grasshopper generative modeling for Rhino.” 2010.

[27] BSI, "BS EN ISO 7243: 2017 - Ergonomics of the thermal environment - Assessment of heat stress using the WBGT (wet bulb globe temperature) index," 2017.

[28] BSI, "BS EN ISO 8996: 2004 - Ergonomics of the thermal environment - Determination of metabolic rate," 2004.

[29] F. R. D’Ambrosio Alfano, J. Malchaire, B. I. Palella, and G. Riccio, "WBGT index revisited after 60 years of use," Ann. Occup. Hyg., vol. 58, pp. 955-970, 2014.

[30] B. Lemke and T. Kjellstrom, "Calculating workplace WBGT from meteorological data: a tool for climate change assessment.," Ind. Health, vol. 50, pp. 267-78, 2012.

[31] T. E. Bernard and M. Pourmoghani, "Prediction of Workplace Wet Bulb Global Temperature," Appl. Occup. Environ. Hyg. ISSN, vol. 14, 1999.

[32] J. C. Liljegren, R. A. Carhart, P. Lawday, S. Tschopp, and R. Sharp, "Modeling the Wet Bulb Globe Temperature Using Standard Meteorological Measurements,” J. Occup. Environ. Hyg., vol. 5, pp. 645$655,2008$.

[33] R. H. Henninger and M. J. Witte, "EnergyPlus testing with ANSI/ASHRAE standard 140-2001 (BESTEST),”Washington, D.C., 2001.

[34] “Energy Plus Weather Data,” EnergyPlus. [Online]. Available: https://energyplus.net/weather. 